\title{
APPLICATION OF RAINFALL INTENSITY - KINETIC ENERGY RELATIONSHIP FOR SOIL LOSS PREDICTION
}

\author{
Khalid F. Hassan
}

Soil and Water Sci. Dept. /College of Agric. and Forestry /Mosul Univ.Iraq

\begin{abstract}
In order to explore the consequences of rainfall intensity - kinetic energy relationships for soil loss, climatologically data for monthly and yearly rainfall depth over period of 30-yrs for Mosul city which is located at northern Iraq, were analyzed for the rainfall erosivity index $\left(\mathrm{EI}_{30}\right)$. The modified Fourneir erosivity (MFI) model was used as an indicator for the combination effect of kinetic energy $(\mathrm{E})$ and maximum rainfall intensity at 30 minute $\left(\mathrm{I}_{30}\right)$ on the soil loss. The results showed that $\mathrm{EI}_{30}$ index was varied within a year and between years of the rainfall records and was ranged from 25.1 to 411.9 metric unit with average 140.3 metric unit .The monthly distribution of $\mathrm{EI}_{30}$ showed that the rainfall erosivity was very sever in four months (50\% of rainy months ) through any year of recorder data and December to March was found to be the most erosive months in the studied region. Regression analysis for $\mathrm{EI}_{30}$ with mean annual rainfall depth showed that the natural log law is the best suitable mathematical function judged their relation and $83.3 \%$ of the changes in $\mathrm{EI}_{30}$ were due to variation in the rainfall depth. .
\end{abstract}

\section{INTRODUCTION}

Rainfall erosivity is a measure of climatic influence on water erosion. When other variables such as topography and vegetation cover are held constant, the rate of erosion is directly related to the level of rainfall erosivity . A number of rainfall erosivity indices have been proposed so that the amount of soil eroded is linearly proportional to rainfall erosivity index. The most commonly used rainfall erosivity index is $\mathrm{EI}_{30}$, where $\mathrm{E}$, is the total kinetic energy per unit area for a storm (MJ/ha.)and $\mathrm{I}_{30}$ is its peak intensity $(\mathrm{mm} / \mathrm{hr})$. Bofen (2003) found that the combination of kinetic energy and peak intensity is almost closely related to the observed amount of soil loss.

There are two forms of kinetic energy considered in rainfall data analysis. First is kinetic energy per unit area per unit time (KER, J. $\left.\mathrm{m}^{-2} \mathrm{~h}^{-1}\right)$ and the second is kinetic energy per unit area per unit depth (KE, J. $\mathrm{m}^{-2} \mathrm{~mm}^{-1}$ ). Wischmeier and Mannering (1978) found that the rain kinetic energy (E) could be predicted by:

$\mathrm{E}=916+(331) \log _{10} \mathrm{I} \quad$, in ft-tons/acre per inch of rain ..(1)

where $I$ is the average rain intensity. $E$ is

given in ft-tons per acre per inch of rain, if intensities in inches per hour are used (for up to $3 \mathrm{in} / \mathrm{hr}$ ). The rain energy is therefore only dependent on rain intensities alone. The maximum calculated kinetic energy using this equation is $1074 \mathrm{ft}$-tons/acre/inch. and is applied to rain intensities of $3.0 \mathrm{inch} / \mathrm{hr}$, and greater. This equation has been used to calculate the rainfall erosivity factor(R) of the USLE and the maps in RUSLE (Uson et al 2002).

However, he recommend the following equation; 
$\mathrm{E}=1099[1-0.72 \exp (-1.27 \mathrm{I})]$, also in $\mathrm{ft}$-tons/acre / inch of rain

Received 24/3/2010 accepted 21/6/2010

Moreover, it has been postulated that the square of rainfall intensity ( $\mathrm{I}^{2}$ ) provides a measure of the rainfall kinetic energy. It was found that $\mathrm{KE}$ has a log-based relationship with rainfall intensity. Empirical relationships widely used in soil erosion studies have generally adopted a $\log _{10}$ basis. A direct relationship between the two KE variants and $\mathrm{I}^{2}$ appears to be absent Brodie et al.( 2007) .Mathematically, Garollina et al. ( 2007) indicated that it is possible to express $\mathrm{EI}_{30}$ (storm kinetic energy*maximum 30-minut intensity)in terms of the rainfall amount;

$$
\begin{aligned}
& \mathrm{EI}_{30}=\mathrm{a} \mathrm{Vr} \\
& \text { Where ; } \quad \mathrm{EI}_{30}=\text { is in } \mathrm{N} \mathrm{h}^{-1} \quad \text { Vr is in } \mathrm{mm}
\end{aligned}
$$

The coefficients $a$ and $b$ are empirical parameters depended on the rainfall pattern. Hussein and Othman (1988) used the rainfall amount to find a tentative estimate for $a$ and $b$. The value of $(b)$ in the power equation was near $3 / 2$. The data were refitted to equal 3 with exponible( $b$ ) fixed at 3/2.

The aim of the present study is to establishing a statistical analysis and modeling of rainfall intensity( I ) and kinetic energy ( E ) relationship for rainfalls data collected from 30-yrs in Mosul city / northern Iraq by using the Modified Fourneir Index. Furthermore, this paper provides a theoretical analysis of the potential inter-relationships between Intensity and kinetic energy of rainfall, as a preface of a wider regional investigation. Estimation of rainfall erosivity is of great importance for soil erosion assessment and has important implication for soil conservation and planning for agricultural land uses.

\section{MATERIALS AND METHODS}

As the origin of rainfall erosivity is linked to climatic dynamics ,there is need to apply climatical methodology to study the erosivity factor of rainfall. Rainfall records for rainy months from 1 october 1972 to 31 May 2002 were used to compute the rainfall erosivity index for Mosul city ( located at Longitude $43^{0} \quad 08^{-} \quad \mathrm{E}$ and Latitude $36^{\circ} \quad 20^{-} \mathrm{N}$ ) at northern Iraq. Climatologically, the area is fell within semi - arid zone because the mean annual rainfall depth ranged between $250-500 \mathrm{~mm}$. The rainfall depth during this period varied within years as well as among years and was below the $30-\mathrm{yr}$ average $(374.5 \mathrm{~mm})$. The erosivity index $\left(\mathrm{EI}_{30}\right)$ for each month and year was calculated by using the modified Fourneir index (Arnoldes 1977) as in the following ;

$\mathrm{EI}_{30}=\mathrm{a}\left[\sum^{\mathrm{n}} \mathrm{Pi}^{2}{ }^{\mathrm{b}}{ }^{\mathrm{b}}\right.$

\section{$\mathrm{P}$}

Where:

$\mathrm{EI}_{30}=$ Average rainfall erosivity index in metric unit $\left\{100\right.$ t.m.Cm.ha $\left.{ }^{-1} \mathrm{hr}^{-1}\right)$. 
$\mathrm{Pi}=$ Rainfall depth of rainy months $(\mathrm{mm})$.

$\mathrm{P}=$ Annual rainfall depth $(\mathrm{mm})$.

$\mathrm{n}=$ The number of rainy months.

$\mathrm{a}$ and $\mathrm{b}$ is a coefficients equal to 0.0302 and 1.93 respectively

The coefficient of determination( $\mathrm{R}^{2}$ ) for this model is 0.83 which is acceptable for the first approximation of $\mathrm{EI}_{30}$ index in Iraq (Hussein 1986 ).The calculated erosion potential for an individual storm designated $\mathrm{EI}_{30}$. The total annual $\mathrm{R}$ is therefore the sum of the individual $\mathrm{EI}_{30}$ values for each rain as follows;

$$
R=\frac{1}{n} \sum_{j=1}^{n}\left[\sum_{k=1}^{m}(E)\left(I_{30}\right)_{k}\right]
$$

Where;

$\mathrm{I}=$ rainfall intensity

$\mathrm{J}=$ the counter for each year used to produce the average .

$\mathrm{k}=$ the counter for the number of storms in a year,

$\mathrm{m}=$ the number of storms $\mathrm{n}$ each year, and

$\mathrm{n}=$ the number of years used to obtain the average $\mathrm{R}$.

Relationships between rainfall erosivity index and mean annual rainfall depth were obtained using linear and power relationships. The equation obtained from the exponential model produced smaller standard error of estimates than the logarithmic model.(Richardo et al.2005).In addition the distribution of mean annual $\mathrm{EI}_{30}$ through the rainy months was also obtained by the following relationships;

$$
(\mathrm{PE}) \mathrm{i}=\frac{\mathrm{Pi}^{2}}{\sum \mathrm{Pi}^{2}}
$$

Where :

$(\mathrm{PE}) \mathrm{i}=$ The erosivity index of the specific month( $\mathrm{i})$.

$\mathrm{Pi}=$ Average monthly rainfall $(\mathrm{mm})$.

$\sum \mathrm{Pi}^{2}=$ Average annual rainfall $(\mathrm{mm})$.

The results were analyzed statistically to determine the best regression equation that could be adequately described the temporal and seasonal distributions of rainfall erosivity $\left(\mathrm{EI}_{30}\right)$ with mean annual rainfall depth and / or monthly rainfall depth using Microsoft Excel and Minitab package programming systems.

\section{RESULTS AND DISCUSSION}

Table( I )summarizes all the actual erosive events $\left(\mathrm{EI}_{30}\right)$ values which were calculated from 30yr (1972-2002) of rainfall records for Mosul city by using the Modified Fourneir Index (MFI)model. The erosivity index $\left(\mathrm{EI}_{30}\right)$ revealed somewhat wide variation in their values. It ranged form 37.4 metric unit at season 1972-1973 to 411.9 metric unit at season 1990-1991 with average of 140.3 metric unit. This variation in $\mathrm{EI}_{30}$ values means that there is a fluctuation 
in the amount of annual rainfall depth during the studied period. The data in table 1 also indicate that EI30 values were not actual lead by the higher mean annual rainfall depth. In other words, the increase in annual rainfall depth is not necessarily accompanied by the increasing in $\mathrm{EI}_{30}$ values. The minimum and maximum values (25.1 and 441.9 metric unit ) of $\mathrm{EI}_{30}$ were obtained from somewhat lower and moderately annual rainfall depth of 176.7 and $335.3 \mathrm{~mm}$ respectively. In this respect, Hudson (1981) reported that there was not obviously association between the $\mathrm{EI}_{30}$ index and mean annual rainfall depth. This result indicated that MFI model was statistically unable to account for year-to-year variability in the rainfall data and the linear relationship between them is very weak. An analysis with the relationships between $\mathrm{EI}_{30}$ and $\mathrm{CV} \%$ also suggested that total variability in the data set could be better represented to have dependable $\mathrm{EI}_{30}$. The result showed that the MFI model was valuable in determining the potential of the rain for causing soil erosion by providing information on long -term total variability in the rainfall amount record. For this reason the mean annual rainfall erosivity $\mathrm{EI}_{30}$ can be considered as a adequately

Table (1) ; Yearly and monthly rainfall depth (mm) and $\mathrm{EI}_{30}$ for Mosul city during

1972-2002 .

\begin{tabular}{|c|c|c|c|c|c|c|c|c|c|c|}
\hline Year & Oct. & Nov. & Dec. & Jan. & Feb. & Mar. & Apr. & May & $\sum$ Pi & EI $_{30}$ \\
\hline $1972-1973$ & 0.5 & 42.2 & 28.2 & 32.7 & 53.5 & 22.6 & 16.5 & 50.8 & 246.5 & 37.4 \\
\hline $1973-1974$ & 0.0 & 23.1 & 28.4 & 111.4 & 95.1 & 172.7 & 39.9 & 3.6 & 474.2 & 283.3 \\
\hline $1974-1975$ & 0.0 & 43.0 & 72.8 & 51.2 & 101.3 & 14.3 & 63.8 & 14.7 & 361.1 & 103.6 \\
\hline $1975-1976$ & 0.5 & 39.2 & $94 . .1$ & 65.3 & 77.6 & 91.4 & 66.7 & EI30 & 471.1 & 111.7 \\
\hline $1976-1977$ & 19.4 & 3.0 & 30.6 & 94.3 & 32.3 & 30.0 & 56.2 & 0.8 & 266.6 & 75.1 \\
\hline $1977-1978$ & 7.4 & 19.5 & 99.9 & 77.4 & 80.0 & 35.1 & 5.9 & 4.2 & 329.4 & 119.6 \\
\hline $1978-1979$ & 0.8 & 23.0 & 56.5 & 78.8 & 45.7 & 49.4 & 10.1 & 1.8 & 266.1 & 68.3 \\
\hline $1979-1980$ & 19.2 & 49.4 & 79.9 & 21.3 & 165.5 & 81.9 & 83.1 & 0.7 & 501.0 & 223.4 \\
\hline $1980-1981$ & 3.1 & 75.1 & 112.2 & 59.4 & 52.1 & 97.1 & 27.1 & 5.8 & 431.9 & 143.2 \\
\hline $1981-1982$ & 26.6 & 56.6 & 47.3 & 97.0 & 41.9 & 9.8 & 85.9 & 24.4 & 389.5 & 95.7 \\
\hline $1982-1983$ & 15.0 & 90.3 & 46.0 & 40.5 & 49.2 & 40.0 & 18.9 & 27.7 & 327.6 & 63.6 \\
\hline $1983-1984$ & 1.0 & 54.8 & 18.2 & 17.8 & 15.9 & 105.3 & 18.9 & 35.4 & 267.3 & 87.2 \\
\hline $1984-1985$ & 18.4 & 174.4 & 36.0 & 52.5 & 50.9 & 78.6 & 52.9 & 1.5 & 465.2 & 217.1 \\
\hline $1985-1986$ & 3.0 & 23.9 & 38.1 & 31.5 & 121.6 & 37.6 & 44.1 & 9.4 & 309.2 & 106.1 \\
\hline $1986-1987$ & 26.0 & 59.4 & 43.3 & 18.3 & 126.2 & 71.6 & 8.4 & 1.3 & 354.5 & 134.3 \\
\hline $1987-1988$ & 84.7 & 12.0 & 120.8 & 198.3 & 104.3 & 98.2 & 45.2 & 2.5 & 666.0 & 340.8 \\
\hline $1988-1989$ & 3.6 & 18.8 & 95.3 & 14.9 & 45.5 & 97.7 & 1.3 & 3.4 & 280.5 & 128.6 \\
\hline $1989-1990$ & 7.3 & 133.5 & 25.8 & 52.4 & 77.5 & 38.6 & 29.7 & 0.3 & 365.1 & 146.5 \\
\hline $1990-1991$ & 4.0 & 6.2 & 47.9 & 28.5 & 32.0 & 205.6 & 9.0 & 2.1 & 335.3 & 411.9 \\
\hline $1991-1992$ & 0.2 & 44.6 & 82.6 & 97.8 & 132.8 & 24.6 & 27.2 & 55.4 & 465.2 & 166.8 \\
\hline $1992-1993$ & 0.0 & 109.2 & 123.9 & 49.8 & 85.9 & 18.8 & 171.4 & 144.1 & 703.1 & 230.8 \\
\hline $1993-1994$ & 17.1 & 66.7 & 73.1 & 76.5 & 47.3 & 93.8 & 63.7 & 2.9 & 441.1 & 111.0 \\
\hline $1994-1995$ & 18.2 & 68,6 & 68.6 & 37.2 & 65.7 & 104.7 & 39.0 & 16.5 & 418.5 & 102.1 \\
\hline $1995-1996$ & 0.7 & 30.2 & 10.1 & 166.9 & 34.9 & 121.6 & 38.7 & 16.5 & 419.6 & 268.3 \\
\hline $1996-1997$ & 6.1 & 8.7 & 132.9 & 45.6 & 75.9 & 48.7 & 12.9 & 11.5 & 342.3 & 151.4 \\
\hline
\end{tabular}




\begin{tabular}{|c|c|c|c|c|c|c|c|c|c|c|}
\hline $1997-1998$ & 38.9 & 23.3 & 83.0 & 81.1 & 32.6 & 48.5 & 19.5 & 24.8 & 351.7 & 73.1 \\
\hline $1998-1999$ & 0.1 & 0.1 & $9.7 \cdot$ & 36.8 & 48.2 & 19.8 & 11.7 & 1.2 & 127.6 & 26.8 \\
\hline $1999-2000$ & 10.5 & 08.2 & 28.0 & 52.6 & 23.7 & 31.1 & 22.3 & 0.3 & 176.7 & 25.1 \\
\hline $2000-2001$ & 12.4 & 46.7 & 83.7 & 25.9 & 37.9 & 82.5 & 36.2 & 17.6 & 342.9 & 76.3 \\
\hline $2001-2002$ & 2.60 & 11.1 & 48.3 & 55.4 & 17.9 & 126.1 & 77.4 & 1.1 & 339.9 & 81.6 \\
\hline Average & 11.5 & 40.3 & 65.1 & 62.3 & 65.6 & 69.9 & 40.1 & 15.6 & 370.4 & 140.3 \\
\hline
\end{tabular}

described the seasonal and temporal distribution of rainfall erosivity . It was showed from table $(2)$ that the coefficients of determination $\left(\mathrm{R}^{2}\right)$ for the five obtainable models were ranged from ( 0.301$)$ to $(0.833)$ and the best-fit model of these relationships which strongly correlated the erosivity index $\left(\mathrm{EI}_{30}\right)$ values with the event rainfall depth is fitted by an exponential relationships ( Model No.4 in table 2 );

$$
\mathrm{Y}=101.3 \quad \ln \quad \mathrm{X}-126.7+\mathrm{E}
$$

Where:

$\mathrm{Y}=$ Predicted EI30 ( Metric unit ) and $\mathrm{E}=$ random, normally distributed error

$\mathrm{X}=$ Mean annual rainfall depth $(\mathrm{mm})$.
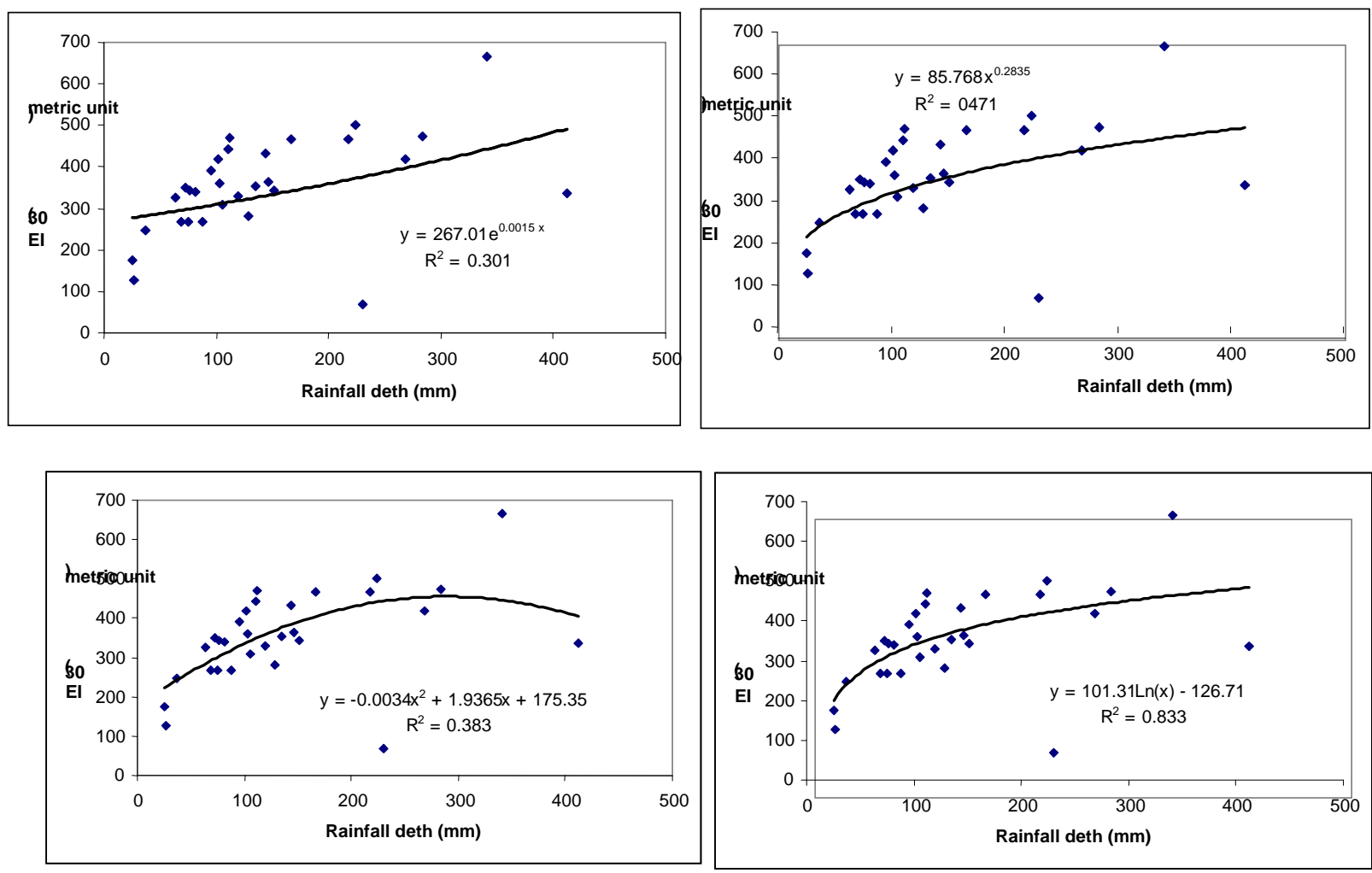


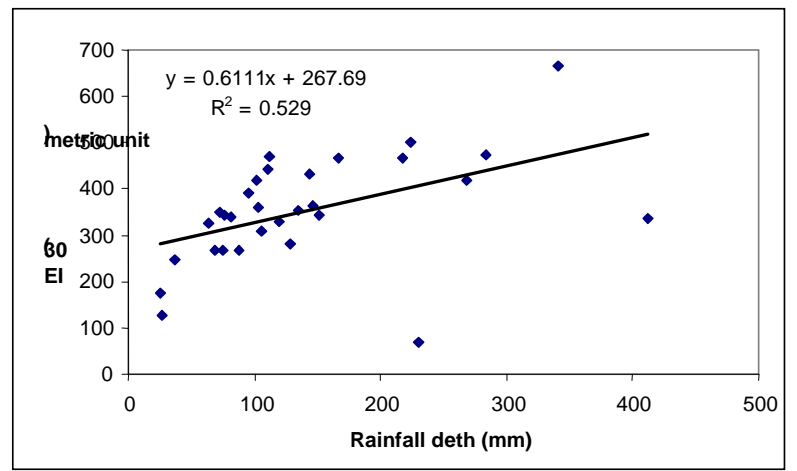

Fig.( 1 ): Linear and curvilinear relationships of $\mathrm{EI}_{30}$ to mean annual rainfall depth

The high value of coefficient of determination $\left(\mathrm{R}^{2}\right)$ amounted to $(0.833)$ .and the was highly correlated and the model was more accepted to be used. The significant results obtained ,indicate that about $83.3 \%$ of the change in $\mathrm{EI}_{30}$ was due to the amount of annual rainfall depth. This mean that the $\mathrm{EI}_{30}$ was not only associated with the amount of rainfall depth, but also on the natural distribution of rainfall through the year. In the regressed analysis, all data were used to obtain the relationship and all coefficients of determination were significant at 0.05 level probability.

Although ,the 30-yr of rainfall data were used to calculate the average value of erosivity index $\left(\mathrm{EI}_{30}\right)$, the estimated value of $\mathrm{EI}_{30}$ (140.3 metric unit ) for Mosul in our study, was somewhat higher and overestimated than those predicted by the isoerodent map of Iraq which was presented by Hussein (1986) for rainfall depth

data collected over the period of 1940-1980 which was also constructed using MFI model. This variation in calculated $\mathrm{EI}_{30}$ between the two investigations could be attributed to the variation in the period which used in each study .

Table (2): Regression equations and $\mathrm{R}^{2}$ for $\mathrm{EI}_{30} *$ Annual rainfall depth Relationship

\begin{tabular}{|c|c|c|c|c|}
\hline Seq. & Models & Intercept (a) & Slope $(\mathrm{b})$ & $\mathrm{R}^{2}$ \\
\hline 1 & $\mathrm{Y}=267.01 \mathrm{e}^{0.005 \mathrm{X}}$ & 0.000 & 267.00 & 0.301 \\
\hline 2 & $\mathrm{Y}=85.76 \mathrm{X}^{0.206}$ & 0.000 & 85.76 & 0.471 \\
\hline 3 & $\mathrm{Y}=0.6111 \mathrm{X}+267.69$ & 0.6111 & 267.69 & 0.529 \\
\hline 4 & $\mathrm{Y}=101.31 \mathrm{Ln} \mathrm{X}-126.71$ & -126.71 & 101.31 & 0.833 \\
\hline 5 & $\mathrm{Y}=0.0034 \mathrm{X} 2+1.9365 \mathrm{X}+17.51$ & 17.51 & -0.0034 & 0.529 \\
\hline
\end{tabular}

Al-Jobori (1984) indicated that the semi-average method could be used successfully for describing the trend of annual $\mathrm{EI}_{30}$ over any period. This method, in brief, the original data of $\mathrm{EI}_{30}$ were divided into two groups of equal period .The values of each group were then summed up and averaged . The average of each group was centered in the period of the time of the group from which it has been calculated and then plotted on the graph.. The slope of the line joining the two parts give the trend. A positive slope implies increasing trend and negative slope for decreasing trend .In the present study , the actual 
data were divided into $15 \mathrm{yrs}-15 \mathrm{yrs}$ periods .The first $15 \mathrm{yrs}$ period included data of 1972-1987 season and the second 15yrs period include data of 1987-2002 season. Table (3) and figure (2) had shown that there was an increasing in the average $\mathrm{EI}_{30}$ from 124.6 to 156.1 metric unit for the $1^{\text {st }}$ group $(1972-1987)$ and $2^{\text {nd }}$ group (1987-2002) respectively.

This result means that there was a positive trend equal to +31.4 metric unit in the values of yearly $\mathrm{EI}_{30}$ through the studied period, and this result interpreted the variation between the average value of $\mathrm{EI}_{30}$ in this study and the $\mathrm{EI}_{30}$ value of isoerodent map of Hussien(1986).

Table (3): Detailed statistical parameters (Semi-average , St. deviavtion and C.V.) of $\mathrm{EI}_{30}$

\begin{tabular}{|c|c|c|c|c|c|}
\hline Gr. & Yrs record & Semi-total & Semiaverag & St.deviation & C.Variation \\
\hline 1 & $72-1987$ & 1869 & 124.64 & 67.663 & $54.28 \%$ \\
\hline 2 & $87-2002$ & 2347 & 156.07 & 112.230 & $71.91 \%$ \\
\hline
\end{tabular}

Separation the data of $\mathrm{EI}_{30}$ index into two groups of equal periods( $15 \mathrm{yr}$ ), the mean annual $\mathrm{EI}_{30}$ shows a decrease( MFI1-15 = 124.6 metric unit ) in the $1^{\text {st }}$ group of rainfall record (1972-1987) and increase gradually (MFI2-15= 156.1 metric unit) during the $2^{\text {nd }}$ group( 1987-2002). In detailed ,the calculated mean annual $\mathrm{EI}_{30}$ for the total period (1972 - 2002) was slightly above the mean annual of the $1^{\text {st }}$ group (1972-1987) and was below the mean annual of the $2^{\text {nd }}$ group (1987-2002). Because of the data set were widely different in their means, the standard deviation and C.V \% were more better to use for comparison between the two groups. The high value

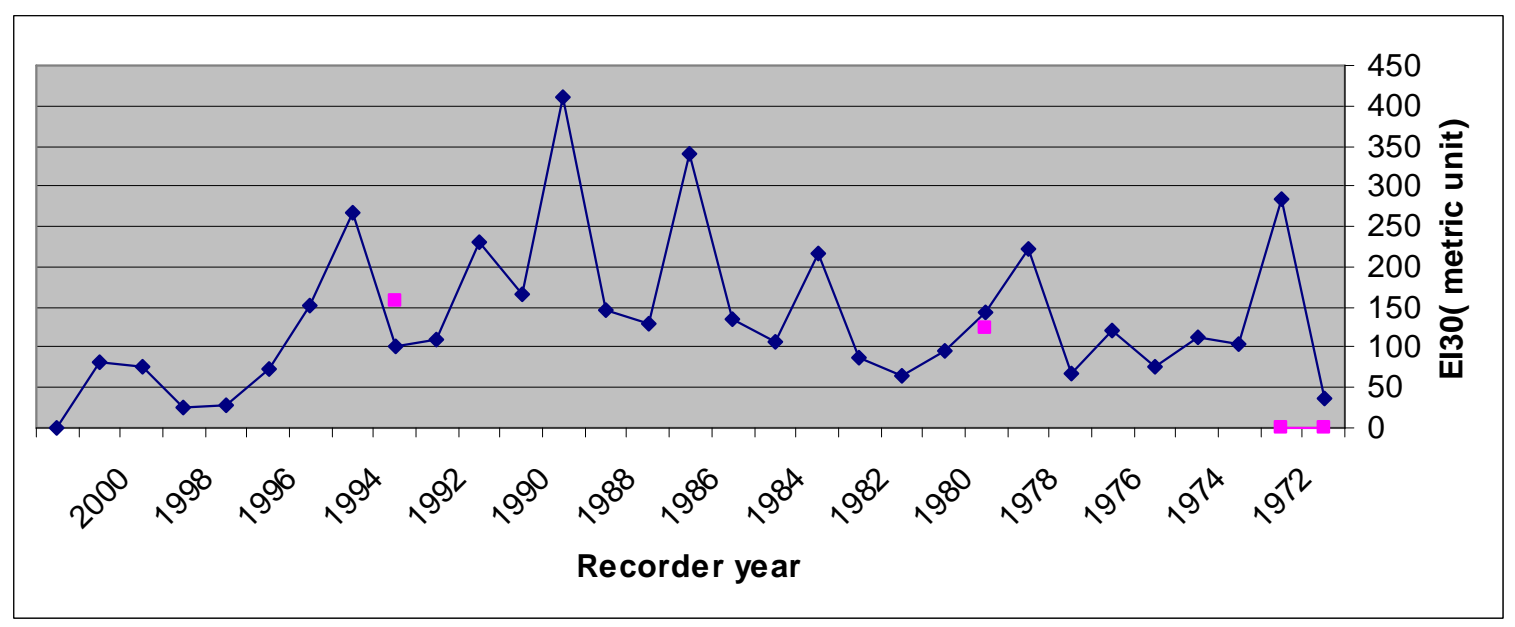

Fig.( 2 ): The trend of actual $\mathrm{EI}_{30}$ by Semi-Average Method.

of standard deviation(123.23) for the $2^{\text {nd }}$ group, in comparison with the standard deviation(67.633) of the $1^{\text {st }}$ group, means that the actual data of the $\mathrm{EI}_{30}$ have a high variance in their distribution (in comparison with the $\mathrm{EI}_{30}$ of the $1^{\text {st }}$ group) through the years of the rainfall records used in this study, and this result can show clearly from the C.V. \% value for the two groups of rainfall recorder (table 3 ) in which the C.V.\% value of the $2^{\text {nd }}$ was less than 
that of the $1^{\text {st }}$ group. On the other hand ,the distribution of estimated annual $\mathrm{EI}_{30}$ ( percent of annual erosivity index) by rainy months and $30-\mathrm{yr}$ average along the rainy seasons are presented in Table (4). It can be seen that approximately $(21.9 \%)$ of annual erosion was concentrated during March $(21.9 \%),(19.7 \%)$ in February and $(18.8 \%)$ in January while it decline to $(17.4 \%)$ in December and $(11.9 \%)$ in November and decrease to $(6.4 \%)$ and (2.8) and (1.1\% )in April, May and October respectively. These results give an idea that the rainfall erosivity was very sever in four months $(50 \%$ of rainy months) through any year of rainfall records and December to March was found to be the most erosive months in the studied region The summation of mean monthly $\mathrm{EI}_{30}$ (as shown in Fig 3 ) was considered as a good indication to smoothing the $\mathrm{EI}_{30}$ movement to predict event soil loss for area under study over period 1972-2002.

The Actual Soil Erosion Risk ( ASER ) produced by the monthly return frequencies of rainfall event for 10yrs(MFI-10 $=126.1$ metric unit ) ,20yrs $($ MFI-20 $=153.1)$ and 30yrs (MFI-30 = 140.3 ) year as accumulative periods showed a significant improvement and agreement with the line of curvilinear ( non-linear ) of

$\mathrm{EI}_{30} *$ average rainfall depth relationships of the studied area. Therefore, the empirical equation explain the relationship is ;

$\mathrm{Y}=-\mathrm{I} .582+0.281256 \mathrm{X}$

$\mathrm{R}^{2}=0.998$ )

Where ; $\mathrm{Y}=$ acc. $\mathrm{EI}_{30}$ in metric unit and $\mathrm{X}=$ mean annual rainfall depth in $\mathrm{mm}$.

Table ( 4 ): \% erosivity $\left(\mathrm{EI}_{30}\right)$ distribution for rainy months at the studied area over period 1972-2002.

\begin{tabular}{|c|c|c|c|c|c|c|c|c|}
\hline Year & Oct. & Nov. & Dec. & Jan. & Feb. & Mar. & Apr. & May \\
\hline $1972-1973$ & 0.0 & 18.0 & 8.1 & 10.8 & 28.9 & 5.2 & 2.8 & 26.2 \\
\hline $1973-1974$ & .0. & 0.98 & 1.5 & 22.9 & 16.7 & 55.0 & 2.9 & 0.1 \\
\hline $1974-1975$ & 0.0 & 7.6 & 21.7 & 10.7 & 41.8 & 0.8 & 16.6 & 0.9 \\
\hline $1975-1976$ & 0.0 & 4.4 & 25.4 & 12.3 & 17.3 & 24.0 & 12.8 & 3.8 \\
\hline $1976-1977$ & 2.5 & 0.1 & 6.1 & 58.1 & 6.8 & 5.8 & 20.6 & 0.0 \\
\hline $1977-1978$ & 0.2 & 1.6 & 41.4 & 24.9 & 26.6 & 5.1 & 0.1 & 0.1 \\
\hline $1978-1979$ & 0.0 & 3.7 & 21.9 & 42.6 & 14.3 & 16.7 & 0.8 & 0.0 \\
\hline $1979-1980$ & 0.7 & 4.8 & 12.6 & 0.9 & 54.1 & 13.2 & 13.6 & 0.0 \\
\hline $1980-1981$ & 0.1 & 16.2 & 36.3 & 10.2 & 7.8 & 27.2 & 2.1 & 0.1 \\
\hline $1981-1982$ & 2.8 & 12.6 & 8.8 & 37.1 & 6.9 & 0.4 & 29.1 & 2.3 \\
\hline $1982-1983$ & 1.4 & 47.1 & 12.3 & 9.4 & 14.1 & 9.2 & 2.1 & 4.4 \\
\hline $1983-1984$ & 0.0 & 18.0 & 2.0 & 1.9 & 1.5 & 67.1 & 2.0 & 7.5 \\
\hline $1984-1985$ & 0.7 & 66.1 & 2.6 & 5.8 & 5.5 & 13.3 & 6.0 & 0.0 \\
\hline $1985-1986$ & 0.0 & 2.6 & 6.8 & 4.6 & 69.5 & 6.6 & 9.4 & 0.5 \\
\hline $1986-1987$ & 2.5 & 12.9 & 6.8 & 1.3 & 57.8 & 18.4 & 0.3 & 0.0 \\
\hline $1987-1988$ & 8.6 & 0.2 & 17.4 & 46.9 & 13.0 & 11.5 & 2.4 & 0.0 \\
\hline
\end{tabular}




\begin{tabular}{|c|c|c|c|c|c|c|c|c|}
\hline $1988-1989$ & 0.1 & 1.6 & 42.6 & 1.1 & 9.7 & 44.8 & 0.0 & 0.1 \\
\hline $1989-1990$ & 0.2 & 60.0 & 2.2 & 9.3 & 20.2 & 5.0 & 3.0 & 0.1 \\
\hline $1990-1991$ & 0.1 & 0.1 & 4.9 & 1.7 & 2.2 & 90.8 & 0.1 & 0.0 \\
\hline $1991-1992$ & 0.0 & 4.9 & 16.9 & 23.7 & 43.6 & 1.5 & 1.8 & 7.6 \\
\hline $1992-1993$ & 0.0 & 13.7 & 17.5 & 2.8 & 8.4 & 0.4 & 33.5 & 23.7 \\
\hline $1993-1994$ & 0.9 & 14.3 & 17.2 & 18.9 & 7.2 & 28.3 & 13.1 & 0.1 \\
\hline $1994-1995$ & 1.2 & 16.7 & 16.7 & 4.9 & 15.3 & 38.9 & 5.4 & 0.9 \\
\hline $1995-1996$ & 0.0 & 1.9 & 0.2 & 59.7 & 2.6 & 31.7 & 3.2 & 0.6 \\
\hline $1996-1997$ & 0.2 & 0.3 & 62.4 & 7.4 & 20.3 & 8.4 & 0.6 & 0.4 \\
\hline $1997-1998$ & 7.6 & 2.7 & 34.6 & 32.9 & 5.3 & 11.9 & 1.9 & 3.1 \\
\hline $1998-1999$ & 0.0 & $.0 \cdot$ & $2.2 \cdot$ & 31.5 & 54.0 & 9.1 & 3.2 & .0 \\
\hline $1999-2000$ & 1.9 & 1.2 & 13.6 & 48.1 & 9.8 & 16.8 & 8.6 & 0.0 \\
\hline $2000-2001$ & 0.8 & 11.0 & 35.2 & 3.3 & 7.2 & 34.2 & 6.7 & 1.6 \\
\hline $2001-2002$ & 0.1 & 0.4 & 8.3 & 11.4 & 1.1 & 57.2 & 21.5 & 0.0 \\
\hline Average & 1.1 & 11.9 & 17.4 & 18.8 & 19.7 & 21.9 & 6.4 & 2.8 \\
\hline
\end{tabular}



Equation

Furthermore, although almost all factors of the Universal Soil Loss (USLE) were influence by changing in climate, it was evident that the rain erosivity factor ( $\mathrm{R}$ ) was of primary importance and directly involved (Carollina et al 2007). The formula for the USLE is :

$\mathrm{A}=\mathrm{RKLSCP}$

Where;

$\mathrm{A}=$ Mean annual soil loss

$\mathrm{K}=$ Soil erodibility factor

$\mathrm{R}=$ Rainfall erosivity factor

$\mathrm{S}=$ Slope gradient factor

$\mathrm{L}=$ Slope length factor

$\mathrm{C}=$ Cropping system and soil management factor

$\mathrm{P} \mathrm{P}=$ Supporting practices factor

In the original formula of the USLE, the R-factor was calculated as a product of total kinetic energy by the maximum rainfall intensity at 30-minut.Since this rainfall parameter are not readily available, the $\mathrm{EI}_{30}$ of MFI was taken into account to determine the rainfall erosivity as a function of soil loss. Then the erosivity index $\mathrm{EI}_{30}$ by MFI model is similar and equal to the erosivity index ( $\mathrm{R}$-factor )in equation 9 ), therefore the equation becomes;

$$
\mathrm{A}=\mathrm{f}(\mathrm{R}) \mathrm{klscp}
$$

Where ; $\mathrm{R}=\mathrm{EI}_{30}$ (metric unit) and klscp $=$ constant

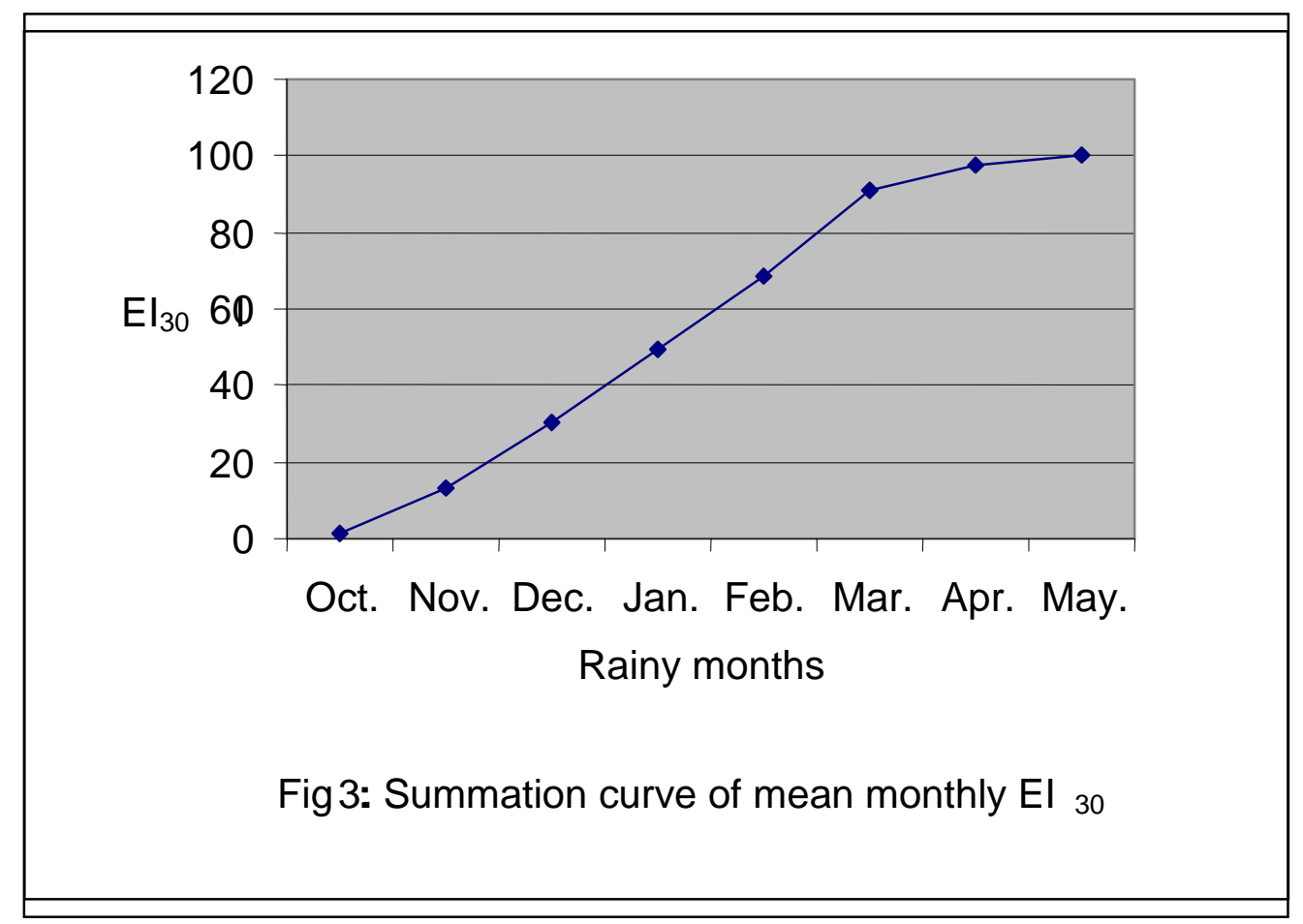

This conceptual mean that when factors other than rainfall are held constant, soil loss directly proportional to rainfall erosivity index $\left(\mathrm{EI}_{30}\right)$. Therefore, the mean annual $\mathrm{EI}_{30}$ are represented the mean annual soil loss which removed from the studied region yearly. From the result obtained in this study, it may be concluded that in semi - arid condition ,serious rainfall erosion 
(sheet and rill) often occur ,because the rain although low in quantity, it could come in very sever storm, and the estimation of rainfall erosivity index for this region is a key point for the selection of soil conservation system ( Hussien 1986 and Bayramin et al 2006) and the analysis of MFI value with additional data over period 1972-2002 showed that the studied area was under the moderate erosion risk according to the erosivity classes of Soil Conservation Service ( SCS) especially in winter and spring season.

$$
\text { استخدام علاقة الثدة المطرية بالطاقة الحركية للتنبؤ بمعدل فقل التربة }
$$

\section{الخلاصة}

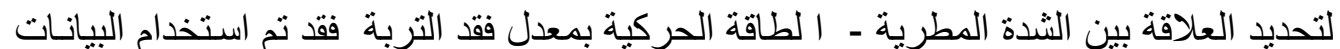

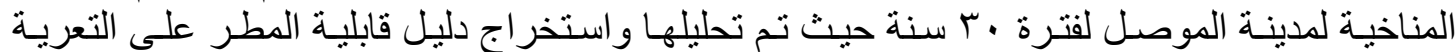

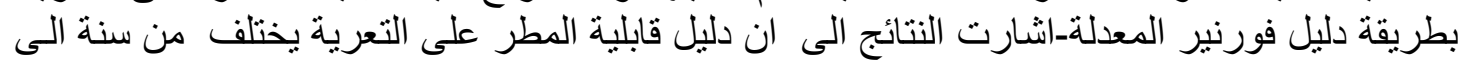

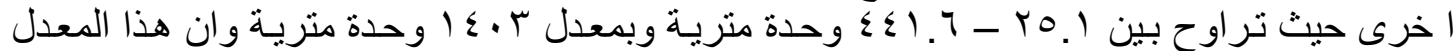

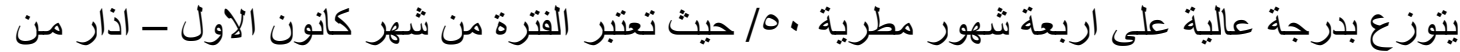

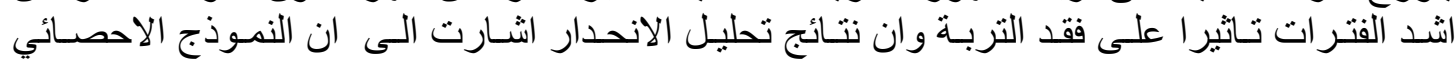

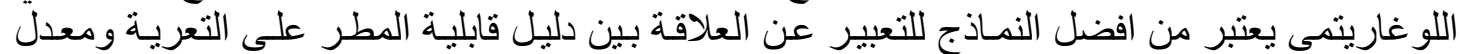

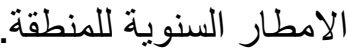

\section{REFERENCES}

Al-Joboori ,S.(1984).Trends and prediction of annual rainfall in Iraq. JAWRR. 3:121-130.

Arnoldus, H. M.J. (1977).Methodology used to determine the maximum potential mean annual soil loss due to sheet and rill erosion in Morocco. FAO Soils.Bull.34. United Nation ,Rome, Italy

Aslan,Z. (1997). Analysis of Rainfall Erosivity and Climatic Factor of Wind Erosion. Inter. Centre for Theoretical Physics.

Bayramin, I., G. Erpul and H . Erdogan .(2006 ). Use of corine methodology assess soil erosion risk in the semi- arid area of Beypazari / Ankara, Turk .J. Agri. For. 30: 81 - 100.

Brodie, Ian and Roswell, Colin J. (2007). Theoretical relationships between rainfall Intensity and kinetic energy variants associated with storm water particle wash off. J. of Hydrology, 340 (1-2). pp. 40-47. ISSN 00221694.

Garollina, M., G. Gruz and R. Mario.( 2007 ). Long - term variation in rainfall erosivity in Uruguay Geo. Journal. 70:257-262.

Garbrecht, J.D. (2008). Multi-year precipitation variations and watershed sediment arid area of Beypazari / Ankara, Turk .J. Agri. For. 63:70-76 .

Hussein, M. .H.(1986).Rainfall erosivity of Iraq. J. Soil and Water Conservation. $41: 336-338$.

Hussein, M. H. and M.K. Othman.(1988). Soil and water losses in low intensity rainfall region in Iraq. Hydrological Sci. 3;257-267. 
Richardo, L. F. Hans ,R. Vermeulen and D. Nieuwenhuis (2005). Kinetic energy -rainfall intensity-energy in southern Nigeria .Climatic change. 6:151-164.

Salak , F.K. (2008) Rainfall variability and kinetic en relationship for central Cebu. Philippines for soil J of Hydrology 30:20- 28.

Uson, A., and M. Ramose(2001).An improved rainfall erosivity index obtained from experimental inter-rill soil losses in soil with a Mediterranean climate (Article ) CATRENA , 43:293-305.

Wischmeir, W. H. and D. D. Smith(1978) .Predicting Rainfall Erosion Loss .A guide to Conservation Planning .Agr. Hand book.No.537.USDA..

Ya Bofen (2003) Erosion and precipitation .Encyclopedia of Water Sci .Ed. Marcel and Bekker. Australia. 